\title{
Brinquedo e Educação: na Escola e no Lar
}

\author{
Edda Bomtempo ${ }^{1}$ \\ Instituto de Psicologia - USP
}

\begin{abstract}
Resumo
Como o artigo mostra, brinquedo, brincar e jogar são considerados de grande importância para o desenvolvimento humano. Os tópicos considerados são: aprender brincando ou brincar para aprender; papéis educacionais dos brinquedos e jogos; os professores e os brinquedos; brinquedos e jogos no lar e na escola; o lar como um lugar divertido. Pais e professores precisam estar informados do valor dos brinquedos, brincadeiras e jogos para o desenvolvimento das crianças e dos adolescentes.

Palavras chave: brinquedo, brincar, jogo.
\end{abstract}

\section{Toy and Bducation: at school and at home}

\section{Summary}

Toy, play and game are considered of great importance to the human development as the papel' shows. The issues considered are: learning in play or play to learning; the educational roles of toys and games; teachers and play; toys and games at home and school; the home as one entertaining place. Parents and teachers must be informed of the value of toys, plays and games to the children and adolescents development.

Key words: toy, play, game.

\section{O Brinquedo na Escola}

Muitos teóricos têm enfatizado a importância do brincar sob vários pontos de vista. Para Piaget (1951), o jogo é fator de grande importância no desenvolvimento cognitivo. O conhecimento não deriva da representação de fenômenos externos, mas sim, da interação da criança com o meio ambiente. O processo de acomodação e assimilação é meio pelo qual a realidade é transformada em conhecimento. No brincar, a assimilação predomina e a criança incorpora o mundo à sua maneira sem nenhum compromisso com a realidade. Neste sentido, brincar é parte ativa, agradável e interativa do desenvolvimento intelectual.

Para Vygotsky (1967), há dois aspectos importantes no brincar: a situação imaginária e as regras. A situação imaginária criada pela criança, preenche necessidades que mudam de acordo com a idade. Um brinquedo que interessa a um bebê não interessa a uma criança mais velha. As regras presentes no brincar não são regras explícitas, mas que a própria criança cria o desenvolvimento desses dois aspectos delinea a evolução do brinquedo das crianças.

Para Denzin (1975), a atividade lúdica é um meio de ensinar a criança a se colocar na perspectiva do outro. No brincar, interações face a face com uma ou mais pessoas são desenvolvidas, orientando os comportamentos cognitivos e simbólicos.

Brincando, a criança se inicia na representação de papéis do mundo adulto que irá desempenhar mais tarde. Desenvolve capacidades físicas, verbais e intelectuais, tomando capaz de se comunicar. O jogo ou brinquedo são, portanto, fatores de comunicação mais amplos do que a linguagem, pois propiciam o diálogo entre pessoas de culturas diferentes.

\footnotetext{
${ }^{1}$ Endereço: Rua Cristiano Viana. 670. apto. 112 CEP: 05411-000 - São Paulo - SP - Brasil.
} 
Freud (1922) e alguns de seus seguidores, como Melanie Klein (1982) e Aberastury (1972), situam o brincar como meio de aliviar experiências dolorosas, criar fantasias para atender as necessidades não satisfeitas ou cuja expressão foi reprimida.

Pesquisas que enfatizam o brinquedo como material motivador são fundamentais para o treino de habilidades cognitivas, verbais e sociais.

Comparando tipo de programas, as pesquisas mostram que embora o jogo não seja uma estratégia melhor que as outras, é de alto valor para complementar um programa bem sucedido. Não é a quantidade de material que leva a melhor aprendizagem, mas a habilidade de lidar com ele. Dessa forma, o envolvimento do professor no jogo é vital.

Comparando também, o ensinar com brincadeiras e sem brincadeiras, os resultados mostram que, nem sempre, ensinar com brincadeiras é mais eficiente, apontando que o excesso de informações ou atenção a informações irrelevantes pode influir negativamente na aprendizagem. Neste sentido, é de suma importância o professor saber como passar a informação ao aluno.

Kamii e Devries (1991) chamam a atenção para o brincar em grupo, que tem significado diferente e especial para as crianças pequenas, que aprendem mais através de jogos que com lições e uma infinidade de exercícios. Alguns critérios devem ser levados em conta para que o jogo possa ser útil no processo de ensino-aprendizagem:

- ser interessante e desafiador;

- permitir a participação de todos os jogadores do princípio ao fim;

- permitir a auto-avaliação

A utilização do jogo simbólico ou de faz-de-conta é outro recurso de grande valia, pois. proporciona um maior desenvolvimento cognitivo e social à criança.

O jogo sociodramático ou de representação de papéis é considerado por Piaget (1964) a mais alta expressão do jogo simbólico, pois possibilita à criança o desenvolvimento de habilidades como audição, discriminação, classificação de sons, identificação e verbalização, dando base para interpretação de várias experiências. Smilansky (1968), Rosen (1974) e Griffing (1980) apontam a influência do jogo socio-dramático na solução de problemas.

Nowak (1994) analisa como o jogo simbólico ou de faz-de-conta contribui para o desenvolvimento cognitivo. Cognição, criatividade, substituição, expressão, socialização etc. são atribuídas a esse tipo de jogo. A brincadeira com cartas pode ser um precursor do desenvolvimento da leitura, uma habilidade cognitiva. A função criativa é demonstrada pelos papéis e características que ocorrem ao longo da brincadeira.

No jogo simbólico a criança expressa medos e preocupações e representa emoções observadas na vida real, começa e termina a construção e a organização de seu mundo, forma e reforma a realidade de acordo com suas necessidades. Assim, o jogo simbólico é um elemento necessário ao desenvolvimento intelectual e emocional da criança.

Estudos sobre o brincar como um facilitador da aprendizagem avaliam os efeitos das características espaciais da sala de aula, uso do equipamento e posicionamento no espaço, divisão de áreas espaciais, limites de espaço comuns e privativos e nível de barulho.

Alguns pesquisadores relatam que o equipamento posicionado centralmente recebe mais uso e encoraja um brincar mais interativo do que o de canto (Witt e Gramza, 1969). 
Brinquedos e brincadeira facilitam o ensino e aprendizagem, principalmente das crianças préescolares, porém, nada valem sem a intervenção adequada do professor.

As pesquisas sobre o brincar aumentaram nos últimos anos, porém, seu impacto junto aos educadores ainda é discutível, por dois motivos:

A orientação filosófica dos professores é fator importante para determinar o impacto das pesquisas sobre o brincar na educação atual. Muitos professores ainda têm restrições à utilização de jogos e brinquedos em sala de aula. Respostas imaginativas e brincalhonas aos problemas são freqüentemente desencorajadas e a interação social com amigos é considerada perturbadora da classe. O brincar dirigido prevalece em detrimento do brincar espontâneo. Os professores devem começar a ver a criança pequena como um ser que necessita de novas informações através de experiências concretas, vendo a si mesmos como facilitadores.

O brincar deve fundamentar-se em pesquisas que mostrem seu valor para o desenvolvimento da aprendizagem e possam convencer a administração da escola e a família dos alunos de sua importância.

\section{Aprender Brincando ou Brincar Para Aprender?}

O brincar e a escola nunca estiveram em plena concordância. Para pedagogos, de Platão a Schiller e de Comenius a Rousseau, o jogo ou brinquedo é o método mais eficiente de aprendizagem para criança. Porém, existe diferença entre aprender brincando e brincar para aprender.

"Aprender e brincar são realidades que fazem parte do reino da liberdade" (Bousquet 1986, p.S02). Um exercício escolar pode ser realizado como um jogo e este como tarefa escolar, perdendo seu componente lúdico.

O jogo, dentro do processo educativo, deve ser mescla de repetição e surpresa, deve estimular o interesse dos participantes com a introdução de elementos inesperados, agradáveis e difíceis, aproveitando o momento para chegar com entusiasmo a esse descobrimento. É o aprender brincando.

A proposta de um novo jogo a ser jogado na Escola deve começar pela observação e compreensão de quem está melhor habilitado para o jogo - a criança (Marcelino, 1990).

É ela que vai mostrar o caminho a seguir através dos seus brinquedos e brincadeiras. É importante que nós, educadores, mergulhemos no universo tão rico da criança para melhor compreendê-la, chegando mais perto de suas necessidades.

\section{Papel Pedagógico do Brinquedo e do Jogo}

A introdução do brincar no currículo estimula o desenvolvimento físico, cognitivo, criativo, social e a linguagem da criança pequena (Saracho, 1991). Para muitos professores, é um trabalho de pagens "baby sitting", por isso, não encorajam as crianças a brincadeiras espontâneas, o que, às vezes, bloqueia a imaginação das crianças e habilidades para solucionar problemas, interpretando interações sociais com pares durante o brincar como mau comportamento. Isso porque os professores têm dificuldade para justificar as atividades lúdicas no ensino. 
É preciso que os professores entendam que atividades e experiências alternativas promovem a aprendizagem da criança através do brincar. O professor pode selecionar, organizar e apresentar objetos, materiais, sup011es e experiências para desenvolver conceitos ou temas. Antes de qualquer intervenção, fazer observações sistemáticas do brincar da criança para identificar elementos críticos que podem não estar presentes, o que lhe possibilita conhecer a representação de papéis, a manipulação de materiais e a linguagem. A intervenção deve revitalizar, clarificar e explicar o brincar, não dirigir as atividades (Christie, 1982).

A introdução de brinquedos e brincadeiras no currículo escolar requer espaço e materiais, estímulo à interação entre as crianças e compreensão por parte dos professores das diferentes formas de brincar, relevantes para cada criança em determinado momento.

Os programas educacionais, raramente, preparam os professores para usar estratégias que promovam o brincar das crianças. Para Rothlein e Brett (1987), os professores acreditam que o brincar é alegre e possibilita o desenvolvimento cognitivo e social. Para Sylvia, Roy e Palmer (1980), os professores agem assim por considerar o brincar como coisa de criança. A intervenção do professor afetaria a oportunidade e a progressão do brincar, impedindo a criança de distinguir realidade e fantasia.

Saracho (1991) aponta dois tipos de intervenção no brincar das crianças: participativo e dirigido.

Participativo: quando a interação do professor visa a aprendizagem incidental durante o jogo: as crianças encontram um problema e o professor ajuda-as na solução; quando estimulam a criança a usar a imaginação durante o jogo, o que pode levar a criança a ser menos repetitiva, mais inventiva ou a elaborar temas.

Dirigido: o professor aproveita o jogo para a aprendizagem de conteúdo de currículo. No jogo de construção, a criança constrói alguma coisa de acordo com o seu interesse. O professor intervém perguntando sobre o peso, a medida e o tipo de construção realizada. Em geral, no estilo dirigido o professor dirige as atividades para situações não lúdicas, desvalorizando o brincar, que deixa de ser espontâneo, impedindo o desenvolvimento da criatividade.

A intervenção do professor não deve tolher a imaginação criativa da criança, mas orientá-la, deixando que a brincadeira espontânea surja na situação de aprendizagem, pois é através dela que a criança se prepara para a vida em seus próprios termos. Respeitando o jogo, o educador poderá desenvolver novas habilidades no repertório de seus alunos.

Muitas pesquisas sugerem que o professor que percebe quando deve pal1icipar encoraja mais a criatividade da criança. As pesquisas mostram que as intervenções não específicas podem oferecer várias possibilidades e estimular a criatividade da criança (Mellou, 1995).

\section{Ensinando Professores a Brincar}

Se estamos convencidos de que o brincar facilita a aprendizagem, é preciso que o docente goste de brincar. Professores que saibam brincar são indispensáveis para o êxito deste empreendimento. Há necessidade de uma mudança no que se refere à atitude do professor frente à situação de ensino-aprendizagem.

Os professores não estão ainda convencidos de que os jogos são fator de ativação e 
estruturação das relações humanas, contribuindo para o estabelecimento da comunicação dos alunos entre si e com os professores.

O brincar, exigindo atividade pessoal, permite uma prospecção para o futuro, convidando a criança a explorar todas as suas possibilidades e não somente as propostas pelos adultos.

É fundamental que o adulto respeite as características da criança em cada situação, considerando sua capacidade, idade emocional e fase de desenvolvimento (Winnicott, 1975).

O simples dividir da experiência lúdica entre adultos e crianças faria praticamente desaparecer a relação de poder existente entre eles. (Jacquim, apud Marcelino, 1990). No brincar pais e educadores não são mais os mestres onipotentes, pois obedecem às mesmas regras que a criança.

Estabelecidas as regras do jogo, o processo educacional estará baseado na liberdade, não em ameaças, castigos e humilhações. A educação pode ser proposta e vivida como uma grande aventura (Dallari), 1986, apud Marcelino, 1990). "É o prazer de estudar, de investigar, de perguntar que faz da educação uma coisa bonita, gostosa, brinquedo, feito empinar pipa" (Alves, 1984, p.191).

Para Leif e Brunelle (1976), é importante lembrar:

1. Nada será feito em favor do brincar, se os professores não se interessarem por ele.

2. Observar as crianças no decorrer de seus brinquedos e jogos é um dos melhores meios de conhecê-las. Enriquece e exige uma formação psicológica dos professores. Participar dos jogos dos alunos pode instaurar uma relação autêntica com eles.

3. À competência profissional é preciso acrescentar o entusiasmo, a criatividade, a alegria de viver, a aptidão para as relações humanas e a abertura de espírito, complementados pela formação contínua.

Um professor formado nesse espírito entenderá o brincar da criança. A reflexão sobre a natureza e limites de sua intervenção evitará que ele se torne organizador, sem abdicar de seu papel de animador.

\section{O Brinquedo no Lar}

A brincadeira para a criança é necessária por sua contribuição ao desenvolvimento da habilidade de aprender a pensar.

Para adquirir essas compreensões a criança necessita de grande variedade de experiências repetidas e concretas. Para Piaget (1975), a criança aprende, compreende e se comporta intelectualmente através de intensas interações com o seu ambiente, de acordo com o seu estágio de desenvolvimento.

Batendo, apalpando ou virando um objeto, a criança está tentando defini-lo pelo seu uso. Se durante a exploração, obtém um resultado inesperado, sua tendência é reproduzi-lo através de movimentos que o provocaram. Esse tipo de comportamento, segundo Piaget, caracteriza o surgimento das primeiras condutas inteligentes, pois a criança começa a desenvolver e a combinar esquemas com meios e fins. Para ela, o contato com o objeto já não consiste em um simples exercício do esquema, mas na compreensão do objeto em si e sua relação com ela mesma. A criança dominará a qualidade dos objetos, somente através de sua relação com eles. Ela tem de 
experimentar, sentir, cheirar, ouvir e manipular os objetos até que os conheça tão bem que não necessite mais tê-los fisicamente presentes para saber como são e como se comportarão em grande variedade de circunstâncias. Significa que a criança progride da necessidade de experimentar alguma coisa para a habilidade de pensar sobre ela.

Dando à criança acesso a diferentes tipos de materiais como cubos, tintas, areia, água, brinquedos de diferentes tamanhos e formas, bem como a liberdade para explorá-los à sua maneira, estaremos proporcionando o desenvolvimento de sua habilidade de reconhecer objetos e ações de distingui-los entre si, de tomar consciência de suas similaridades e diferenças e, finalmente, de abstrair, classificar e simbolizar. E tudo isso virá, naturalmente, de uma rica e ativa vida de brincadeiras.

Passo importante no desenvolvimento do pensar é o início da solução de problemas que envolvem atitudes como: desejo de fazer perguntas, experimentar de maneiras diferentes objetos já conhecidos, fazer coisas etc. Para desenvolver essas atitudes nada melhor do que as brincadeiras do dá e tira.

Todo o comportamento da criança pode ser estudado através de suas atividades lúdicas que, se fossem encaradas seriamente pelos adultos, poderiam resolver muitos dos problemas afetivosociais e de aprendizagem.

De acordo com Zimmermann e Calovini (1971), o brinquedo deve ser atraente, bem construído, seguro, não tóxico e, sobretudo, desafiador. Acrescentaria, além disso, que ele deve estimular a curiosidade e a imaginação da criança, levando-a a descobrir coisas novas e diferentes e fantasiar sobre elas. Para isso não é necessário que este brinquedo seja sofisticado, eletrônico, automático ou de controle remoto...

Nas sociedades de consumo, o brinquedo é um produto industrial, fonte de grandes lucros, objeto de ampla publicidade, exibido em feiras e vitrines reluzentes. Um sinal de riqueza e prestígio social, que pode tornar-se fonte de desigualdade entre crianças da mesma escola ou vizinhança.

Relações amigáveis muitas vezes são rompidas pela competição, baseada no valor dos brinquedos possuídos. O brinquedo sofisticado perde grande parte de suas qualidades lúdicas, por ser objeto acabado que limita a criatividade e a imaginação. Seria preferível a criança brincar com um objeto simples - uma pedra, ou em pedaço de pano ou de pau que possa transformar à vontade em instrumento musical, ferramenta, arma, carro, boneca ou bicho - do que com brinquedos que, embora chamem a sua atenção, levam à saciação rápida, porque não permitem alternativas nem fazer algo diferente. Se não for quebrado ou transformado, o brinquedo logo ficará relegado ao esquecimento.

Embora queiram a felicidade dos filhos, os pais nem sempre estão cientes do que a criança precisa. Muitas vezes, ela pede um brinquedo apenas porque o amiguinho o tem ou pela força da propaganda. Hoje a propaganda é mais controlada e, muitos brinquedos têm o selo do INMETRO.

O brinquedo é um objeto que reproduz valores e conceitos de uma sociedade. Ele é o parceiro da criança na brincadeira. A manipulação do brinquedo leva a criança à ação e representação, a agir e imaginar.

Manipulação, posse, consumo... O brinquedo introduz à criança a operações associadas ao objeto. A apropriação se inscreve num contexto social: o brinquedo pode ser mediador de uma relação com outra ou com uma atividade solitária, mas sempre sobre o fundo da integração a uma cultura específica. Além disso, o brinquedo é igualmente suporte de representações, introduzindo a 
criança num universo de sentidos e não somente de ações. O brinquedo valoriza hoje o imaginário em detrimento a um realismo estreito. O mundo representado é mais desejável que o mundo real. A brincadeira aparece, assim, como um meio de sair do mundo real para descobrir outros mundos, para se projetar num universo inexistente. Brougere (1990).

Assim, o brincar da criança não está somente ancorado no presente, mas também tenta resolver problemas do passado, ao mesmo tempo que se projeta para o futuro. Por exemplo: a menina ao brincar com bonecas, vai repetir aquilo que observa a mãe fazendo na rotina da casa. Vai tirar e colocar a roupa da boneca, aprender a escolher cores e modelos, a pentear o cabelo. Depois, vai pentear o próprio cabelo. No fundo, brincar de boneca é uma bela e instigante experiência a respeito da estética feminina. A criança transfere para o dia-a-dia as atividades da brincadeira com a boneca. Da mesma forma, o menino que brinca com carrinhos aprende a repetir os sons do motor, da buzina, a diferença entre o que é rápido e o que é lento.

De modo geral, os adultos não sabem comprar brinquedos. Muitas vezes escolhem coisas que as crianças não usam. São objetos de aparência bonita, que elas não entendem e, muitas vezes, abandonam logo depois de abrir o pacote. Os pais precisam confiar mais na capacidade de escolha das crianças. O correto é perguntar aos filhos o que gostariam de ganhar. O primeiro critério na escolha de um brinquedo é saber se ele é adequado ao desenvolvimento da criança. Ex.: jogos com regras complexas, não servem para uma criança com menos de 5 anos.

Os pais, sempre que possível, devem brincar com os filhos. Pais que brincam com seus filhos são mais felizes porque compreendem melhor as crianças. Para entrar no universo das crianças é necessário descer ao nível delas: sentar no chão, andar de quatro etc...

Relações de poder desaparecem na brincadeira, pois as regras são as mesmas para adultos e crianças. Os pais devem fazer esforço para se lembrar de como brincavam quando eram pequenos. Precisam também, conhecer os brinquedo dos filhos. Essa experiência costuma ser muito gratificante.

Os pais também devem limitar os espaços da brincadeira. Cozinha e banheiro não são lugares para brincar. Se for possível, é bom que ela tenha seu quarto de brinquedo. Porém, os pais não devem impor nada. Devem, isso sim, conversar para explicar as razões de cada determinação.

Quanto às armas de brinquedo é preciso ressaltar que um revólver de brinquedo não toma ninguém mais agressivo do que já é por natureza. Quando a criança brinca com armas que emitem luzes e sons, está representando coisas da vida real. É uma maneira de fantasiar e aprender sobre o mundo tão inofensiva quanto jogar botões ou videogame. O problema está quando o brinquedo se parece demais com um revólver de verdade. Nesse caso, a criança não saberá diferenciar o brinquedo de uma arma. Isso pode até gerar um acidente doméstico, caso os pais tenham uma arma guardada em casa.

Outra idéia falsa dos adultos a respeito das crianças é a brincadeira de super-heróis. A não ser que tenha algum distúrbio psicológico, a criança sabe muito bem o que é de verdade e o que é de mentirinha. A brincadeira de super-herói pode ser considerada uma forma especializada de jogo de papéis ou sociodramático.

O ambiente é de suma importância para a criança. Livre para explorar, de acordo com seu ritmo, e autocontrolar suas atividade, o ambiente a encoraja a uma série de descobertas e lhe dá respostas imediatas.

As propriedades espaciais são aprendidas, quando as crianças se penduram em cordas, andam 
em labirintos, balançam o corpo através de arcos, tentam enfiar-se em lugares menores do que elas ou criam espirais, girando e correndo no playground.

Os passeios em família são muito importantes. Os pais devem evitar lugares sofisticados, principalmente, se têm filhos menores de 12 anos. Normalmente, até essa idade as crianças gostam de ficar à vontade e não sabem se comportar em situações formais.

- Dividir com o filho a responsabilidade de fazer a programação. Selecionar alguns passeios (no máximo 3) e deixar a decisão final para a criança.

- Variar o programa de uma semana para a outra. Se tem sido dado ênfase as atividades físicas, não se esquecer de optar também por passeios que colaborem para o desenvolvimento intelectual, como assistir a uma peça teatral ou visitar um museu.

- Associar programas diferentes em um mesmo dia, como andar de bicicleta no parque e, depois, ir ao cinema. Dessa forma, os acordos familiares tornam-se mais viáveis. Passeios preferidos pelas crianças: circo, visitas a fazendas, zoológico, museus etc...

\section{Diversão em Casa}

Muitas vezes, principalmente as crianças menores preferem ficar em casa, cercadas pelos brinquedos prediletos e na companhia dos pais ou amiguinhos.

Nessa situação, o melhor é não insistir em incluí-las em planos de passeio e sugerir brincadeiras que até podem envolver toda a família: teatrinho, adivinhações, saraus musicais. Caso elas nunca queiram sair ou estejam sempre às voltas com as mesmas atividades, como videogame e filmes em vídeo, vale a pena interferir. Por meio de conversas, livros ou mesmo de anúncios de TV e jornais, procurar então, despertar o interesse delas para atividades que estão fora do lar.

\section{Conclusão}

Com o brincar as crianças dão significado as suas vidas. As pesquisas podem ajudar os adultos a entender os significados que as crianças dão a suas experiências e, a facilitar o brincar.

Para os professores, as pesquisas sobre o brincar possibilitam organizar e observar o brincar das crianças.

Para traduzir a pesquisa em prática, é preciso definir os objetivos do brincar, os processos de desenvolvimento e ou aprendizagem que desejam influenciar, o que exige constante observação dos resultados educativos da brincadeira.

Devemos estar cientes de que, brincando a criança está aprendendo sobre o mundo, porém, os professores necessitam observar as crianças que brincam para perceber o tipo de estratégias que poderiam facilitar a aprendizagem.

Está claro, que atividades de brincar e aprendizagem estão inter-relacionadas e que certos tipos de aprendizagem são facilitados por cel10s tipos de jogos e brincadeiras. O que varia é a intervenção do adulto que, dependendo da atividade, pode ser mínima ou altamente estruturada. 


\section{Referências}

AberastUl)', A. (1972). A criança e seus jogos, Ed. Vozes, Rio de Janeiro.

Alves, R. A. (1984). Conversas com quem gosta de ensinar. Ed. Cortez, São Paulo.

Bomtempo, E. (1987). Aprendizagem e brinquedo. In: Witter, G. P. e Lomônaco, J. F. Psicologia da Aprendizagem: áreas de aplicação. EPU, São Paulo, cap.l.

Bomtempo, E. (1991). A representação da boneca "Barbie" em crianças na faixa etária entre 7 e 10 anos (em colaboração). Revista Brasileira de Pesquisa em Psicologia, 3 (01), 75-83.

Bomtempo, E. (1988). Brinquedo, linguagem e desenvolvimento. In Azevedo, M. A. (org) Pretextos de Alfabetização Escolar: algumas fronteiras do conhecimento. CODAC/USP. Vol. 2, 23-40.

Bomtempo, E. e Marx, R. B. (1993). O que as crianças dizem sobre a boneca "Ganha-Nenê ": Resumos das Apresentações do XXIV Congresso Interamericano de Psicologia, Chile, 271.

Bomtempo, E.; Hussein, C. L. e Zamberlan, M. A. R. (1986). Psicologia do Brinquedo: aspectos teóricos e metodológicos. EDUSP, Nova Stella, São Paulo.

Bomtempo, E. (1996). A brincadeira de faz-de-conta: lugar do simbolismo, da representação, do imaginário. In: Kishimoto, T.M. (org) Jogo, Brinquedo, Brincadeira e a Educação. Cortez Editora, São Paulo.

Bousquet, M. M. (1986). Lo que incita a jugar y 10 que incita a aprender. Perspectivas, vol. XVI, $n^{\circ}$ 4,497507.

Christie,1. F. (1982). Sociodramatic play training. Young Children, 37 (4), 25-32.

Denzin, N. K. (1975). Play games and interaction: the contexts of childhood socialiation. In: Sociological Quartely, 16(4),458-478.

Freud, A. (1922). Além do princípio do praze., Londres, International Universities Press.

Klein, M. (1982). Psicologia. Editora Ática, São Paulo.

Griffing, P. (1980). The relationship between socioeconimic status and sociodramatic play among black kindergarten children. Genetic Psychology Monographs, 101, 3-34.

Leif, J. e BrunelIe, L. (1976). O jogo pelo jogo, Zahar Editores, Rio de Janeiro.

Marcelino, N. C. (1990). Pedagogia da animação, Cadernos de Pesquisa nº 93, 5-11, 1995, São Paulo, Papirus.

Mellow E. (1995). Review of the relationship between dramatic play and creativity in young children. In Early Child Development and Care, July, Vol. 112, 85-107.

Nowak, F.K. (1994). Can symbolic play prepare children for their future? Early Child Development and Care. Sep. Vol. 102, 63-69.

Piaget,J. (1951). A formação do símbolo na criança. Zahar Editores, Rio de Janeiro.

Piaget, 1. (1975). O nascimento da inteligência na criança. Rio de Janeiro, Zahar.

Rosen, C. E. (1974). The effects of sociodramatic play on problem-solving behavior among culturally disadvantaged pre-school children. Child Development, 45,920-927.

Rothlein, L e Brett, A. (1987). Childrens, teachers, and parents perception of play. Early Chidhood Research Quarterly, 2,45-53.

Saracho, O. N. (1991). Educational play in early childhool education. Early Child Development and Care, vol. 66, 45-64.

Smilansky, S. (1968). The effects of sociodramatic play on disadvantaged preschool children. New York: Wiley.

Sylva, K; Roy, C. e Palmer M. (1980). Adults at play. In: Wood, DJ. (Ed) Working with under fives. London: GrantMc Intyre Ypsilanti, Michigan: High Scope Press.

Vygotsky, L. S. (1933). Play and its role in the mental development of the child. Soviet Psychology, 5, 6$18,1967$.

Winnicott, D. W. (1975). O brincar e a realidade, Rio de Janeiro, Imago Editora Lida.

Witt, P. A. e Gramza, A. F. (1969). Position effects in play equipment preferences of nursey school children. Springfield, Illinois State, Department of Mental Health.

Zimmerrnan, L. D. e Calovini, G. (1971). Toys as learning material for preschool children. Exceptional Children, 37(38),642-654. 